\title{
3 Monitoring the standard - here, now and in person
}

\section{Detecting accessibility faults as an engaged citizen}

\section{David Wästerfors}

'I'll show you,' he says, and drives around a corner to a sign on the floor.

A few minutes after we meet at the railway station, Richard, a retired engineer in his sixties who uses an electric wheelchair because of a muscle disease, shows me a glaring accessibility fault. It is inside the railway station complex, which is filled with shops, cafés, restaurants and lots of passing travellers. The symbols on the floor instruct wheelchair users to go in a certain direction to find the lift but, as Richard says, it is wrong.

We move in the indicated direction and only find escalators and an ordinary staircase. There is no way for a wheelchair user to proceed. Richard explains that, in fact, one needs to go in another direction for the lift, and shows me the way to a spacious lift. We would certainly not have found it by following the arrows on the floor. The misdirection is because of the ongoing - and long-running - renovation work taking place in the building. Lifts and stairs have been moved to new locations, but some of the signs have still not been moved or changed.

Richard has reported the fault to the managing company.

We go back to the inaccessible escalators and stairs, and consider the difficulty of going up a floor if you know nothing about the station but trust the signs. It might seem a trivial concern, a 'luxury' in the Western welfare state of Sweden, but it can turn out to be an insurmountable barrier, we conclude. Like everyone else, people with disabilities count on infrastructure. They can be as occupied and stressed as anybody else, they can be committed to this or that, and have others depend on them.

As we talk, Alfred shows up. He is Richard's friend and co-worker at a local disability organisation. Like Richard, he is an accessibility detective. Alfred is also in his sixties and has a visual impairment, making it hard for him to see things directly and without a blur. He says that engaging with the work of finding accessibility faults in the local environment has really changed his mindset. He had not thought about it in the same terms before, though disabled himself, but now he can detect poor accessibility 'almost everywhere': in shopping malls, cinemas, museums, squares and parking lots, inside libraries and government buildings, in digital settings and the healthcare service. Edges on streets, pavements and at entrances must be low but

DOI: $10.4324 / 9781003120452-5$ 
still marked, to be manageable both for wheelchair users and the blind. Signs must be written in correctly contrasting colours to be readable for all, and they should be placed at certain heights. Websites must be usable by all users, and in concerts and lecture halls, at receptions and in offices, the acoustic environment must be suitable for a range of hearing impairments.

This is the second time I have met Richard and Alfred. Both are deeply engaged with their volunteer work of identifying and reporting accessibility faults in their municipality in Sweden, including alerting the public and the media. They have published satirical videos about the errors they find, and routinely use the municipality's apps and webpages to report their observations to the traffic department and other institutions, and then they follow up each case to see if and how the fault is rectified. They have good contacts among officials and managers, but they also have to 'nag', as they say, to have the faults amended.

There is 'always something', Richard and Alfred say. Things are never settled; officials and managers are never fully informed. 'Amateurs' - untrained officials - keep showing up and innovations complicate things, as do aesthetic trends. Richard and Alfred find new faults every day. Still, they enjoy their work. It is fun and exciting but at times it also feels endless, the enemy immense.

\section{Accessibility on the ground}

In this chapter I will analyse some of the practical, emotional and personal aspects of engaging in accessibility politics 'on the ground', and how such an engagement is part and parcel of today's society and its paradoxically nebulous accessibility politics. There is a formal equivalent to this engagement within building committees in Sweden's municipalities, since, under the Swedish Planning and Building Act and the prescriptions of the Swedish National Board of Housing, Building and Planning, they should monitor accessibility, initiate supervision and take action whenever they find deviations or shortcomings (see Boverket, 2018). But my focus is not the implementation of formal inspections, or their inherent deficiencies. ${ }^{1}$ Instead, I will consider Richard and Alfred's activities as a form of mundane detective work from the standpoint of the relatively subordinated but attentive citizen. What they do is both similar to and different from what municipalities do - or should do - but it is also an engagement in its own right.

Laypeople detectives are policy-equipped - they know the law and people's rights, are familiar with a range of previous cases (cf. Zotééva, 2018), and keep close contact with the local building committee - but they work also beyond policies. I do not intend to liken their work to inspections by the authorities or policy evaluations, but to keep it as probing, embodied and 'lived' as it seems to be. Richard and Alfred are watching and conceptualising today's resistance to accessibility on their own initiative, and they try to disclose and defeat it in a tangible, 'in the field' manner. Although their 
approach is precise, methodical and accountable - like the municipalities' work is supposed to be - it is also flexible, personal and plastic. To analyse this work is to both recognise and understand people's close-up fights against exclusion and discrimination. The detectives find a orderliness to the world that they see as demonstrably troublesome and illegitimate - it makes the social world unnecessarily constricted - and they call for change.

My approach lines up with the effort to not get trapped in a 'boxy' way of understanding accessibility (Shakespeare, 2014, pp. 33-42). Sometimes we imagine an ideal linearity: society at time 1 is inaccessible and discriminatory, and should be moved to another and superior state at time 2, when it will be accessible and inclusive: 'barrier-free' (Williams-Findlay, 2020, p. 134). This can be done, we presume, through the forceful use of political power, unambiguously informed by the latest declarations of rights, most notably the United Nations Convention on the Rights of Persons with Disabilities (CRPD). Society should, as it were, move from one box to another, removing barriers and, ultimately, transforming the whole social organisation (cf. Shakespeare, 2014, pp. 12-16). Most likely, however, this is not how it happens and the reasons are manifold. First, there is no precedent for such historical shifts, and no good arguments for the existence of a reachable utopia waiting around the corner (Shakespeare, 2014, pp. 34-38). ${ }^{2}$ Rather, there are good arguments that social change takes place stepwise and moves both forward and backward, and that the progression towards increased accessibility entails slowly defeating the new and everchanging forms of resistance or inertia that pop up. Change does occur, but not in the sense of travelling from one discrete box to another. Moreover, society at time 1, the imagined point of departure, is itself fluctuating in several ways - mostly not due to disability politics - and this extends and complicates people's accessibility work. Society is, like the railway station in my introductory example, constantly being reconstructed, so that earlier efforts to ensure accessibility (the signs on the floor) become obsolete and new inaccessibilities emerge. To imagine accessibility as something that is possible to 'get done with' once and for all leads one to gloss over its processual and socially embedded nature - a nature that we often recognise in people's situated experiences and through close-up inquiry (cf. Kastenholz et al. 2015, p. 1278, ${ }^{3}$ see also Patrick Kermit's chapter in this book). Not only is the Fully Accessible Society a moving target, amorphously dynamic depending on people's changing practices, wishes, individual impairments and conditions (Shakespeare, 2014, p. 37), but the point of departure and the means by which to advance also fluctuate.

A boxy way to understand accessibility also glosses over the politics of everyday life. We run the risk of overlooking the fact that politics is part of people's daily practices - sometimes in engagements that are not even defined as politics (Luhtakallio \& Eliasoph, 2017) - and that disability politics is not simply a top-down activity for professional groups and authoritative declarations by seemingly righteous governments. To 'move' society in a disabilityfriendly direction is not only a matter of paragraphs in formal policies, 
decisions or evaluations, but a set of tangible and mundane 'trouble dealings' (cf. Emerson, 2015; Wästerfors, 2021). It is a practical, emotional and even personal project. This is not to say that 'grand' politics and interests should not be taken into account; rather, exclusion and ableism do not merely manifest 'above' us or far away, but here and now, within concrete situations and everyday troubles (see also the chapters by Patrick Kermit and by Elisabet Apelmo and Camilla Nordgren). The rights that the politicians are debating and advocating can be tried, examined and played out in and through the gaze and practices of laypersons who become accessibility detectives in the streets.

\section{Methods, data and concepts}

The research underpinning this chapter emerges from the Swedish research project that initiated this book. It entails a diverse set of data on accessibility, and resistance against it, in various settings in Sweden during 2018-2020. The main methods are qualitative interviews and go-alongs (Kusenbach, 2003). ${ }^{4}$ We interviewed 36 persons of various ages, from various socioeconomic backgrounds and living with various disabilities (mostly physical, but also some cognitive, perceptual and combinations of disabilities). We accompanied around 20 of these informants on their daily errands to get a close and more dynamic understanding of their dealings with accessibility, thereby combining more informal interviewing with fieldnotes and photos. We also interviewed ten representatives of establishments indicated by the persons with disabilities, and collected registered complaints to municipalities (cf. Hanna Egard's chapter in this volume).

As we analysed the data, we started to identify Richard and Alfred - the joint focuses of this chapter - as the main accessibility detectives of our project. Their habit of critically exploring their surroundings, and of inspecting and scrutinising places and situations from an accessibility point of view, really stood out. Still what they do is far from unique. Indeed, poking around and observing faults in one's settings is commonplace in our data (cf. Wästerfors, 2021). Sometimes people do not formally report faults but simply sigh over them, mutter, whine or complain in private, or call the responsible persons and/or upload an image on social media with a critical remark ('here I am, and I cannot do my shopping', cf. Hansson, 2020; Egard \& Hansson, 2020). Richard and Alfred, however, embody what the geographer Rob Kitchin (1998, p. 352) calls 'resisting disablist practices', and they cultivate this within a local association. Their performance summarises and 'thickens' what many of our other informants also do, and since we met them several times, we could ask more about it and revisit their activities (cf. Holstein \& Gubrium, 1995, on active interviewing).

In this chapter, I draw theoretically on ethnomethodology, interactionism, phenomenology and studies of disability politics. I have come to look upon detecting inaccessibility in everyday life as practical action and practical 
reasoning in unity (Lynch, 2001, p. 131). It is done and accounted for, accounted for and done - and it is a local achievement, performed by members of society with experience of disability-and-exclusion, and informed by the norms of how society should, ideally, be. It is a situated exploration of the real-world policies of accessibility and inclusion in materialised forms. It thereby illustrates the double-edged sword of ethnomethodology, both as an active investigation of the methods through which members of a group or setting construct the social word, and a more distant acknowledgment of the investigations already performed, before the researchers entered the scene (Lynch, 2001, p. 132).

Detecting inaccessibility is an embodied, concerted and emotional procedure, anchored in laws and policies. It depends on interactions with others and with the environment, both of which can be said to 'answer' or respond to the investigations and manipulations of the detective who, in one way or another, finds the orderliness problematic in the light of how it should be. It depends on a living subject manoeuvring a body (or parts of it) in a certain place or situation, carefully attending to what does not fit, match, correspond, alleviate, help or include. It involves feelings like indignation and resentment, but also excitement and joy. I suggest that this detection contains a component of folk methodology, one which is personal and sometimes also tacit. As the philosopher Michael Polanyi (1958) describes, it is learned by example and imitation, and it relies on our body. The knowledge produced comes forth by 'dwelling' in things (Polanyi, 1967, p. 18, 21), not by simply applying a theory - even though the detectives certainly are equipped with accessibility norms to use as a yardstick - but by interiorising and extensively using it. The personal aspect shows itself not only in the fact that the detective tries out various places or situations with his or her person at the centre - 'here $I$ cannot enter', 'it doesn't fit me', 'it's too dark for me to see', using a personal subject as a sort of mannequin - but also by the fact that subjects report the faults, legitimise them in person and sign their complaints with their own names. I do not mean to say that this work is personal in the sense that it is dependent on personally experienced disability. It is personal in its engagement and practical accomplishment.

This concreteness and personalness can be contrasted with the abstract declarations and policies of today, and it gives flavour, colour and body to the often rather dry perspectives of authorities and evaluations. Although a systematic assessment of accessibility with a set of recommended strategies as benchmarks is certainly a powerful act, ${ }^{5}$ it is also powerful, in a different sense, to bring experienced 'folk assessors' into social science, to capture their continual practice of assessing and its dynamic sensitivities. Moreover, this has a politically subversive side.

Detecting these faults is, I argue, a downplayed version of dissidence performance. Analogous to the Charta 77 movement in the harsh regimes of the communist bloc in Europe once upon a time, the ulterior motivation is cleverly manufactured: it grips the language of power and reverts it to itself. The 
dissidents of Eastern Europe could say: 'You (the government of Czechoslovakia, at the time) have signed petitions on human rights, then how come this case, and this and this, etc., prove they are not valid?' Similarly, citizens in many states today can argue that given what the governments have actually promised to the disabled, the situation experienced here, now and in person, simply will not do.

\section{Techniques of fault finding}

'You get used to it,' Richard says, using the Swedish phrase det sätter sig, roughly meaning 'it sinks into you', or perhaps something like 'you get configured to doing it', 'it almost becomes automatic'.

When I express mild surprise about all the faults Richard and Alfred show me over the course of a single day, they account for their gaze by referring to the fact that they are now trained in accessibility and can hardly stop detecting faults. During the go-alongs and in interviews, they demonstrate and report their techniques. They look and feel, they point out to one another and describe, they follow the conventional paths for citizens - in the aisles of a shopping mall or a cinema entrance, in pedestrian zones - to check if they are functioning. They go back and check specific junctures or troublesome spots that they have identified and reported before.

Richard, for instance, points to a crossing in the downtown area, saying 'that one we've been "on".' We pass the spot and Richard explains that the pedestrian crossing was 'too narrow' next to the traffic light, so that Richard's electric wheelchair bumped into the signal pole. He dramatises the initial attitude of the roadworks department: 'well, well, we'll change that in two years'. But he got them to do it quicker than that, by 'nagging' and by using a 'good contact'. So, within the detective techniques is also a rhetorical competence and facility in networking. It is not enough to go around 'seeing' faults: one needs to report them and to successfully drive the cases. It helps to go back, report again, follow up on the promised remedies and remind the relevant officials. It is not simply a matter of checking once and spotting errors, but of monitoring settings over time and trying them out repeatedly.

Often, Richard points out, the municipality has some sort of consultant who knows the formal regulations on accessibility - the minimum dimensions of a public toilet, for example - but does not always know why they exist, what their purpose is, as Richard sees it. Then constructors may work with toonarrow margins, or combine things that, taken separately, provide accessibility but, when joined together, actually reduce it (cf. Shakespeare, 2014, p. 37). Richard and Alfred often refer to the need for education, but they are also eager to underline its practical and - in my words - immersive aspects. It is not enough, they say, to know on paper what accessibility means; the consultant or constructor should have tried out a wheelchair themselves, for instance, or walked 'like a blind person' in the streets. Then they would get closer to understanding 'what it's all about,' and would not make so many errors, Richard and Alfred argue. Some municipalities and university programmes do 
include such experiments, and they are often accompanied by personal insights. Alfred dramatises such insights: 'Now, I understand better how it is to not be able to reach the buttons in the ticket machine! ${ }^{6}$

Richard and Alfred offer a wealth of anecdotes with this message. Knowledge of accessibility is better employed, they argue, when it comes with (some kind of) immersion: it goes 'deeper' and becomes more meaningful. Alfred tells me about an occasion when he came across some tilers laying out tactile paths. Out of curiosity, Alfred asked the workers if they knew what these tiles were for. 'They didn't know!' They just did the work of tactile paving, but had no clue about the purpose behind it. If this is the case, no wonder things go wrong sometimes, or 'weird' and 'hasty', as Alfred puts it. He did get the impression that the tilers were doing a good job, but could also imagine the many troubles they might create just by not really knowing what they were doing. Many informants in our research project use a similar line of reasoning to debunk popular arguments based on economics for not providing accessibility in the first place. Many faults could be avoided from the beginning, at no additional cost, simply by knowing more, they argue. They do acknowledge the cost of amending, reconstructing or removing existing structures but, they counterargue, if the responsible actors had known more to begin with, the extra cost would have been avoided.

Thus, embedded in techniques for finding faults is a component of critical review which takes into account politics, the economy, education, various impairments and competence. It is a multi-layered practice with both evaluative and persuasive aspects. When Richard and Alfred walk their rounds, they prepare themselves with arguments and anticipate officials' responses and how to respond to them, moulding their own attitudes, as accessibility detectives, accordingly. They have a catalogue of examples in their minds, and they explicate these to each other and to me, so that they can artfully close the gap between formal (or promised) accessibility and accessibility in situ.

Of course, the formal rules of an accessible pavement or intersection with no barriers are far from tacit: one can look them up on websites and in protocols (see, for instance, Boverket, 2018). ${ }^{7}$ The detective practice that I focus on in this chapter amounts to a bit more. Ethnomethodology helps us here; it is common in such studies to admit and make a point out of the fact that the researcher's temptation to systematise folk methods and their enactments risks transforming them (Lynch, 2001, p. 140). It is hard to systematise what people do, and in trying to do so, it might turn into something else: an abstract logic, a mere application of norms - a boxier view. In situ, detecting what is not accessible is not simply a matter of concluding 'this is not accessible' from a given observation, as if measuring the world with a norm in mind. Rather, it is a routinised practice with several layers and implied ingredients. If we go down the route of ethnomethodology, the researcher's way out of the problem - to potentially over-systematise an everyday phenomenon so that it risks becoming alienated from everyday life - is to describe the members' own ways out (cf. Wästerfors, 2021). Thus, I try to 
describe here Alfred and Richard's ways, which are embodied and lived in their time and their space (Lynch, 2001, p. 142). I do not try to make them more systematic or tidy than they actually are.

It might be helpful to see how I document in my fieldnotes what is happening when Richard and Alfred do not spot a failure of accessibility. At such moments I simply write things like 'he is carefully scrutinising the doorway and the spaces [in the toilet]", "it looks right", he says.' Or: 'We go up and take a look at the exit to the cars and the parking area, which also looks "good".' Sometimes I note that we start talking about other things than the immediate surroundings, since the surroundings seem accessible. We might discuss, for example, Alfred's vision problems, or a previous workplace and its accessibility problems, the problems in the public library, or where we are heading to next, a specific outdoor area, etc. My notes become brief in such passages and the conversations seemingly empty - until we find another failure in the immediate environment to focus on. This is, of course, partly due to the theme of the project and how I communicated it when presenting my research interest, but it also illustrates Alfred's words at the start of this chapter: once you are used to detecting accessibility faults, you start seeing them almost everywhere, and if you do not see any in a particular place, you start hastening to 'the next one'.

In my notes and transcripts, vocabulary itself becomes more elaborated when faults are detected. Richard and Alfred specify their reasonings more, and I ask more follow-up questions. When the role of the meddler or nitpicker has been performed and no more faults seem available, the lights of the 'show' are dimmed and it goes into standby mode.

There is, in other words, a performative aspect to this practice, entailing an expectation to be eloquent, articulate and persuasive 'in character', and more reserved, unobtrusive and terse when there is nothing to comment on. Interactivity is sharpened when you are on the scent. The accomplishment of detecting inaccessibilities requires materials to interact with and, certainly, an audience to engage (see also Elisabet Apelmo and Camilla Nordgren's chapter).

\section{Feeling the faults}

The informants for this research project often vented their frustration at the lack of accessibility. This and related emotions are, I argue, both the most expected and most often displayed in our data. At the very core of the problematic lies frustration; people with disabilities are promised accessibility and yet it does not materialise, not fully or constantly. Our informants talk about the burden of having to point out rights that everybody should know and respect. They mutter or snort when others make way for them, help them out, or act demonstratively 'kind', even though there are laws and policies that guarantee our informants should be able to do things on their own (cf. Wiseman, 2014; Egard \& Hansson, 2020). 
This, we note, may be a motivation for political engagement and is also coupled with discomfort or 'stickiness' in everyday interactions (Hansson, 2012; Wästerfors, 2021). Ideally, society should be designed so that disabilities play no role but, in practice, people's impairments and conditions are brought into focus again and again (Shakespeare, 2014, p. 2633), and situations become awkward easily and for many reasons (cf. Wiseman, 2014, pp. 147-148). Others might feel obliged to not show what they think, and people with disabilities might feel obliged to not show that they understand perfectly what others think, and so on. What Erving Goffman (1963, pp. 83-88; 1971/2010, pp. 219, 224, 267) calls 'civil inattention' - to be seen, but also politely left alone - becomes complicated, and embarrassment in public places is given an extra layer. In the research project we encountered a variety of responses: from informants who refuse to feel embarrassed about the ignorance and blunders of others and retreat into sarcasm, critique, anger or silent sourness, to those who are drawn into embarrassment out of courtesy and feel mortified by the accessibility mistakes and inferior accessibility work of others.

These emotional aspects - associated with accessibility and resistance to it in general - are narrated and touched upon in the encounters with Richard and Alfred, but other feelings are still more striking. There is a sense of fun and excitement in stumbling over new findings and reasoning about them. Richard and Alfred enjoy their activities, even while considering them a serious matter. They talk about the 'absurdities' that the municipality is responsible for, laugh at them and elaborate on sarcastic and entertaining images of ignorant and simple-minded officials. They find it fun to get the officials working, to initiate errands and make their digital reports, engage all those who, on paper, should be engaged in accessibility work, but perhaps tend to forget about it, get distracted, or lapse into laziness. The relative accessibility of the local reporting system that Richard and Alfred use, a website and an app, seems to smoothen and stabilise the process. It is easy to report faults and tick the 'accessibility' box on the form, and when you get a case number back from the municipality it is easy to remember and keep track of it. The very success of their work is also a source of joy; to see things change in their surroundings and to know that their efforts make a difference.

Thus, while frustration is commonplace, other emotions are also involved in the more precise practice of revealing and exposing inaccessibility. There is an 'a ha!' quality to this detective work, as when Alfred looks around in a cinema we visit and brightens up. 'Find a fault!' he says to me, challenging me to see what he sees. I quickly give up, and Alfred explains that there are steps in front of the clearly marked emergency exit, and no lift or ramp. 'You're right', Richard says, 'How did they think there?' - implying, of course, that 'they' did not think at all. Later, we find another emergency exit without steps and our excitement softens a bit, but still the detectives are suspicious. Since there are no clear signs indicating that one exit is suitable for wheelchair users and the other is not, the situation is confusing. In an emergency one might well head towards the impossible exit. 
Embodied perceptions and sensations are integrated into our go-alongs. A too-sharp edge, for instance, is not only a disturbing obstacle on the way from point A to B, cognitively identified and verbally pinpointed. It is also bodily irritating: you feel its existence in your body, you may even sense a sting of pain, and you feel the effort you need to get over it. I have accompanied several people when too-steep (or absent) ramps, for instance, caused a lot of sweat, much like the everyday labour of opening, say, an impossible can or a rusty lock. You have to work at it, repeatedly. Challenges like these can be painful and, as the philosopher Drew Leder (1990, p. 75) points out, they disrupt intentionalities. The actor is in the midst of doing something but gets interrupted and is reminded of his or her body (Hansson, 2020). Even as you bump into an obstacle, you also bump into your own body; the body is not a transcendent means in the background anymore but is suddenly put in the foreground. Wrongly placed tactile tiles are much the same; you 'bump' into a void or a bicycle stand, and the flow of walking is interrupted. This is the disability version of what the sociologist Jack Katz (1999) in his phenomenological study likens to being amputated in traffic, as your driving is cut off by other drivers and you get angry.

When Richard and Alfred try out the bumps in their city and neighbourhoods, encountering them is their intention, so coming across obstacles and exclusion becomes temporarily welcome - it gives them a receipt, so to speak, of their work's importance. Still, the painful side remains. Richard complains about uncomfortable passages (for instance, ways full of bumps and potholes) - 'if I had driven there today, I would have got backpain' - and in a more metaphorical respect there is an underlying pain in their fight against ableism and exclusion at large. Leder (1990, p. 75) argues that pleasure tends to maintain our intentional links to the world (for instance making a bond out of shared enjoyment), whereas pain tends to cut them off, inducing selfreflection and isolation. Pain makes time and space more constricted: 'We are no longer dispersed out there in the world, but suddenly congeal right here' (Leder 1990, p. 75). Our attention is drawn to our own bodies and a particularly painful body part, and the world of potential actions and movements becomes smaller.

Remedying or eliminating this smaller and more constricted world is what accessibility is about. The detectives' mission is to make the world larger and less constricted, for all.

This means that the emotional landscape of monitoring accessibility is patterned but varied (cf. Cahill \& Eggleston, 1994). Next to frustration we find not only lighter forms of discomfort and irritation but also the subtle, sarcastic joy of disclosing society's hypocrisy: things are not as promised.

With some of our informants, there seems to be a distinct contrast between, on the one hand, talking of and observing society's shortcomings - with pleasure, putting the world on stage and your body in the background - and, on the other, relapsing into more private talk of impairments, diagnoses, rehabilitation or habilitation, or just of everyday life, which implies other 
things than the pleasure of political engagement (cf. Apelmo \& Nordgren's reflections on Sara Ahmed's sociology, in their chapter).

The critique of society that we find in the detective business is, in other words, emotionally expansive (Leder 1990, p. 75): filled with new possibilities and pleasures. This is clearly noted during the go-alongs. We point, we sigh and we laugh - all these faults are enjoyable to contemplate. And, on social media, activists create smart entertainment out of this logic of social critique, see for instance \#RampFail, \#Accessibilityfail, \#WheelJoy and Wheelchair Mafia.

\section{Detecting in person}

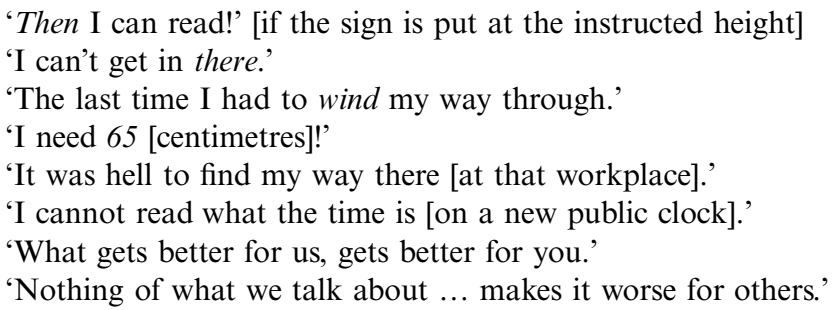

There are many notes and phrases in our data indicating the individual self as a resource. To get close to accessibility in situ and experience how it fails can be greatly facilitated by being there in person, especially if you are informed about laws and policies, and live with a disability or are in close contact with those who do. The lines quoted above can be juxtaposed with the general declarations of the United Nations, such as the right to 'take part on an equal basis with others in cultural life', and that all nations 'shall take all appropriate measures to ensure ... access to cultural materials in accessible formats' (Article 30, CRPD). The UN principles should, in substance, be 'enough'. Everything seems to be there in the convention; a barrier-free society is articulated. But, in practice, the declarations are like a weak magic spell, trying to conjure up an ideal society but only doing so under perfect (unreal) conditions. Richard and Alfred's formulations in interviews and fieldnotes are personal and close to lived experience, whereas the UN declarations are uniform and normative.

The words quoted above, which were spoken by Richard and Alfred at various points during our go-alongs, can also be juxtaposed with official evaluations and reports. Richard and Alfred translate their observations and dress them in uniform terms whenever they report faults, and they have also contributed to official documents. 'I can't get in there' turns into 'impossible to reach the entrance', 'no referrals to alternative entrances' and 'inaccessible door phone' - making for a drier discourse. The personal foundation - the 'I' of the observations - is removed, and both indignation and enjoyment are replaced by factual statements, but still the very detection is personally based. I would not say that accessibility faults always need a person to be detected 
and highlighted, but personal experience may nurture a dynamic and clever critique. To carefully observe accessibility in practice is helped by dwelling on situations and settings (Polanyi, 1967, p. 18, 21), not just quickly inspecting them at a distance and with a form in your hand.

Many of our informants practice a test-it-yourself attitude, and Richard and Alfred epitomise it: acting like a mannequin, measuring arrangements with your own person as - for the time being - the size and standard. To be personal in this work is a way to shift the balance: this is me, and $I$ cannot enter, so it is not accessible enough - rights are not realised, no matter what others say. The ' $I$ ' is, in this respect, far from pointless. Sometimes, informants are met with the argument that there are other and equivalent settings accessible, if not this precise one: again, personal involvement can fruitfully be used here. As Alfred puts it: 'I don't want to go to any pub to drink a beer, I want to enter this pub.' If dressed in subjective terms, even opponents will understand that any pub will not do. My friends are here now, my life is situated, material conditions matter.

A personal foundation for detecting faults can also be a source of disagreement and rhetorical variation. On one occasion, for instance, Richard and Alfred discuss whether they should tell the cashier at a cinema about accessibility concerns in the building. The argument against is 'she cannot do anything anyway', and the argument for is that by informing her she 'gets it into her head' and general awareness increases at the cinema. If you leave behind the protocol, so to speak, and go around yourself to detect faults, it turns into a more personal question how exactly to deal with your findings.

Listening carefully to detectives like Richard and Alfred, though, shows that a personal foundation does not exclude universal ambitions. It is not a matter of putting yourself above others, but of assisting others through your personal example.

That is what is meant by the two last quotes in the list that opened this section: 'what gets better for us, gets better for you', and 'nothing of what we talk about ... makes it worse for others'. Alfred and Richard frequently refer to parents with baby strollers or travellers with heavy luggage who have similar needs to wheelchair users. Most accessibility adaptations are beneficial for all, or at least they do not hinder anybody (cf. Shakespeare, 2014, p. 34, on the academic discussion of universal design). The detective's person is, in a sense, anyone, and his or her client is the citizenry in general.

\section{Conclusion: watching things to make the world less constricted}

In this chapter I have discussed a case of volunteer work to identify and report accessibility faults in urban settings, and conceptualised its practical, emotional and personal aspects. If we look closely at the folk methodology used for this volunteer detection, we find that it is a situated exploration of real-world troubles, embodied and performative, and is continually integrated with painful as well as joyful emotions. It is fun to disclose a hypocritical 
society - there is a clear 'a ha!' quality - but it is also frustrating to, again and again, find new evidence of ignorance and exclusion. It is exciting to try out accessibility yourself, in person, but it can be disheartening that society 'never learns' or only half-heartedly tries to realise its proud declarations and policies issued by a range of standard-setting institutions, from the UN to the municipality building committees. To capture such detective activities, researchers benefit from ethnomethodological, interactionist and phenomenological ways of looking at them, revealing them as broader than merely illustrative examples of citizen engagement.

This is because, on close inspection, it becomes clear that an accessible society is a moving target. It cannot be settled and pinned down due to its own intrinsic conflicts, imperfections and developments, even though accessibility is sketched out in national laws and UN declarations. And, no matter how radical, accessibility will never eliminate all problems associated with various impairments, as Shakespeare (2014, p. 42) points out: 'there will always be residual disadvantage attached to many impairments'. Consequently, accessibility work also needs to be constantly adaptable, strategic and moving. From the point of view of people living with disabilities and personally engaged with the issue, accessibility is not something one can get over and be done with. To commit to watching and improving things in this area is to start using a processual and constantly emerging set of practiced discrimination-sensitivities, a set of elastic and bendable ways of monitoring society.

If society is dynamic, the observation of disability rights must also be dynamic. This is the logic that motivates the detective work and drives it towards multiple and adaptable practices. The detectives are doing a lot: they are watching the setting, measuring it, comparing it with other settings, performing their attentiveness and networks, feeling things and engaging their own bodies for this purpose, drawing on various impairments and relations in their biographies, as well as the law and human rights work, as energising and legitimising yardsticks. They are observing, scrutinising, complaining, reporting, explaining and rejecting others' excuses; they are criticising and controlling, following up on cases and analysing patterns. Detecting these faults is a multi-layered and serious activity.

This seriousness is worthy of note. An accessible everyday life is far from a trivial thing, even though the context of this chapter and my investigation is Sweden's prosperous welfare state with problems that, perhaps, seem rather luxurious. First, what is defined as 'trivial' is a matter of power, where a collective or ideology may kidnap an issue and reduce it to unimportance, for instance by arguing 'well, this library is a bit inaccessible, but you do have access to all books digitally,' or 'well, an inaccessible toilet here or there ... we have so many more important things to take care of in our shopping mall'. ${ }^{8}$ In people's everyday lives, neither public toilets nor libraries need to be seen as trivial, and as social scientists it is our job to study the processes by which such definitions emerge rather than to uncritically accept them. Trivial for whom, and said to be so in which context? 
Second, what is defined as trivial at a certain point might be deadly serious at another or from a general point of view. In October 2016, a disabled woman was found dead in a toilet inside a shopping mall in Malmö, Sweden. ${ }^{9}$ She had attended a conference nearby and got stuck in the toilet, which was most likely equipped with an outdated alarm which was not directly linked to the security guards. The woman's right to personal assistance had also been reduced recently, so she was on her own. She was not found until the following morning. If this had occurred a year ago, a personal assistant said to the Swedish media, "me or somebody else could have stood behind the door' [since at that time, the woman's rights to assistance were wider]. 'It has happened many times that things have not worked out in the [so-called] accessible toilets.'

Accessible toilets and personal assistance are hallmarks of the endeavour to ensure and expand everyday citizenship (Wiseman, 2014, pp. 184-209). As society generates volunteer detectives to monitor how these and other declared rights are treated in practice, social scientists need to conduct studies detecting the character, significance and value of mundane detecting. Even though citizens may rightfully request more efficient inspections from the authorities (cf. Zotééva, 2018), we also need to recognise and understand how laypeople outside offices relentlessly keep an eye on things to make the social world less constricted and less unjust - here, now and in person.

\section{Notes}

1 It has been shown that the municipalities in Sweden do not fulfil their duties when it comes to inspection of accessibility; see Zotééva, 2018.

2 This is true also regarding disability in general, as Shakespeare $(2014$, p. 33$)$ points out: 'Disabling barriers make impairments more difficult, but even in the absence of barriers, impairment can be problematic.'

3 Kastenholz et al. (2015, p. 1278) call for such studies in their article on tourism and accessibility: 'Also an in-depth qualitative approach would be relevant to better understand how these persons [with disabilities] actually manage to overcome some of the identified constraints, which negotiation strategies they use to continue to pursue their desire to travel and why they are mostly not able to overcome other constraints...'.

4 Data were collected together with Hanna Egard and Kristofer Hansson, the other editors of this volume.

5 See, for instance, Mesquita and Carneiro's (2016) assessment of the adaptations of European museums to visitors with visual impairments.

6 See Patrick Kermit's chapter in this volume for a critique of this perspective as an academic statement, and the problems of taking on the role of others in order to understand disability.

7 See also Boverket's website: https://www.boverket.se/sv/PBL-kunskapsbanken/ regler-om-byggande/boverkets-byggregler/tillganglighet/ (accessed 20 January 2021).

8 These are lines informants sometimes say they have heard when complaining about or discussing accessibility in everyday life.

9 See, for instance, SVT Nyheter, the news bulletin on Swedish public service television, https://www.svt.se/nyheter/lokalt/skane/handikappad-hittades-dod-inlast-pa-va rhushustoalett (accessed 20 January 2021), and https://www.svt.se/nyheter/lokalt/ska ne/neuroforbundet-larmet-pa-toaletten-hade-brister (accessed 20 January 2021). 


\section{Wästerfors}

\section{References}

Boverket (2018) Analys av reglerna om enkelt avhjälpta hinder. Rapport 2018: 31. Boverket: Karlskrona. https://www.boverket.se/sv/om-boverket/publicerat-av-bover ket/publikationer/2018/analys-av-reglerna-om-enkelt-avhjalpta-hinder/ (accessed 14 April 2021).

Cahill, Spencer E. \& Eggleston, Robin (1994) Managing Emotions in Public: The Case of Wheelchair Users. Social Psychology Quarterly, 57 (4): 300-312. doi:10.2307/2787157.

Egard, Hanna \& Hansson, Kristofer (2020) Strandsatt och förbisedd - men envis. Erfarenheter av att resa kollektivt med funktionsnedsättning. In: Henriksson, Malin \& Lindkvist, Christina (eds), Kollektiva resor: Utmaningar för socialt hållbar tillgänglighet. Lund: Arkiv Förlag.

Emerson, Robert M. (2015) Everyday Troubles. Chicago: Chicago University Press.

Goffman, Erving (1963) Behavior in Public Places. Notes on the Social Organization of Gatherings. New York: The Free Press.

Goffman, Erving (1971/2010) Relations in Public. Microstudies of the Public Order. New York: Basic Books.

Hansson, Kristofer (2020) Critical Places and Emerging Health Matters: Body, Risk and Spatial Obstacles. In: Atkinson, Sarah \& Hunt, Rachel (eds), GeoHumanities and Health. Cham: Springer International Publishing. doi:10.1007/978-3-030-21406-7.

Hansson, Kristofer (2012) Mellan välvilja och förakt: en etnografi av kategoriseringar i staden. Lambda Nordica, 17 (1-2):102-120.

Holstein, James A. \& Gubrium, Jaber F. (1995) The Active Interview. Thousand Oaks, CA: SAGE.

Kastenholz, Elisabeth, Eusébio, Celeste \& Figueiredo, Elisabete (2015) Contributions of Tourism to Social Inclusion of Persons with Disability. Disability \& Society, 30 (8): 1259-1281. doi:10.1080/09687599.2015.1075868.

Katz, Jack (1999) How Emotions Work. Chicago: University of Chicago Press.

Kitchin, Rob (1998) 'Out of Place', 'Knowing One's Place': Space, Power and the Exclusion of Disabled People. Disability \& Society, 13 (3): 343-356. doi:10.1080/ 09687599826678.

Kusenbach, Margarethe (2003) Street Phenomenology. Ethnography, 4 (3): 455-485. doi.org/10.1177/146613810343007.

Leder, Drew (1990) The Absent Body. Chicago: The University of Chicago Press.

Luhtakallio, Eeva \& Eliasoph, Nina (2017) Ethnography of Politics and Political Communication. Studies in Sociology and Political Science. In: Kenski, Kate \& Hall Jamieson, Kathleen (eds), The Oxford Handbook of Political Communication. Oxford: Oxford University Press.

Lynch, Michael (2001) Ethnomethodology and the Logic of Practice. In: Schatzki, Theodore R., Knorr Cetina, Karin \& Savigny, Eike von (eds), The Practice Turn in Contemporary Theory. London \& New York: Routledge.

Mesquita, Susana \& Carneiro, Maria João (2016) Accessibility of European Museums to Visitors with Visual Impairments. Disability \& Society, 31 (3): 373-388. doi:10.1080/09687599.2016.1167671.

Polanyi, Michael (1958) Personal Knowledge. London: Routledge and Kegan Paul.

Polanyi, Michael (1967) The Tacit Dimension. London: Routledge.

Shakespeare, Tom (2014) Disability Rights and Wrongs Revisited. London \& New York: Routledge. 
Wästerfors, David (2021) Required to be Creative. Everyday Ways for Dealing with Inaccessibility. Disability \& Society, 2 (36): 265-285. doi:10.1080/09687599.2020.1720610.

Williams-Findlay, Bob (2020) The Disabled People's Movement in the Age of Austerity: Rights, Resistance and Reclamation. In: Hart, Emily Luise, Greener, Joe \& Moth, Rich (eds), Resist the Punitive State. Grassroot Struggles Across Welfare, Housing, Education and Prisons. London: Pluto Press.

Wiseman, Philippa J. G. (2014) Reconciling the 'Private' and 'Public'. Disabled Young People's Experiences of Everyday Embodied Citizenship. Glasgow: School of Social and Political Sciences, College of Social Sciences, University of Glasgow.

Zotééva, Anna (2018) Hur Sveriges kommuner hanterar frågor om enkelt avhjälpta hinder. Stockholm: Independent Living Institute. 